\title{
EROTISMO VERSUS MASOQUISMO NA TEORIA FREUDIANA
}

\author{
Isabel Fortes*
}

\section{Resumo}

Neste artigo, pretendemos aproximar a problemática do masoquismo na psicanálise da experiência erótica. A partir do texto de Freud "O problema econômico do masoquismo” (1924), buscaremos diferenciar dois modos distintos de abordagem teórica desta noção. De um lado, situamos um masoquismo mortífero, fruto da submissão ao outro e da culpabilidade, que pode ser definido por meio dos masoquismos feminino e moral. De outro lado, uma outra experiência do masoquismo pode ser vislumbrada com o conceito de masoquismo erógeno, o qual podemos aproximar do erotismo. Este modo de masoquismo é desenvolvido a partir da perspectiva da mescla pulsional, sendo o remanescente do momento do encontro originário entre Eros e pulsão de morte. É condição de possibilidade dos outros dois masoquismos, mas situa-se em um nível estrutural teórico diferente daqueles. Neste sentido, o masoquismo erógeno aponta para um modo de prazer que não se dirige pelo princípio do prazer, mas por um prazer que, por poder existir simultaneamente à dor, é uma experiência de intensidade e de potência eruptiva.

Palavras-chaves: masoquismo, erotismo, pulsão, prazer, desprazer

\begin{abstract}
EROTICISM AND MASOCHISM IN FREUDIAN THEORY

In this article we aim at bringing near the issue of masochism in psychoanalysis and that of erotic experience. Starting from Freud's text The economic problem of masochism (1924), we will try to distinguish two different theoretical approaches to this notion. On one side, we place a deadly masochism, offspring of the submission to the other and of guilt, which can be defined through feminine and moral masochism. On the other side, another experience of masochism
\end{abstract}

* Psicanalista; Professora Colaboradora do Programa de Pós-Graduação em Teoria Psicanalítica do Instituto de Psicologia da Universidade Federal do Rio de Janeiro (UFRJ), com Bolsa de Fixação de Pesquisador da FAPERJ. 
can be glimpsed through the concept of erogenous masochism, which we can bring near to eroticism. This kind of masochism develops from the perspective of instinctual blend, being a remnant of the moment of original encounter between Eros and death drive. It is a condition of possibility for the other two kinds of masochism, but is situated at a different structural theoretical level. In this sense, the erogenous masochism points to a kind of pleasure that isn't driven by the pleasure principle, but by a pleasure that is an experience of intensity and eruptive power, for it can exist simultaneously with pain.

Keywords: masochism, eroticism, drive, pleasure, displeasure

Não há dúvida quanto a que a noção de masoquismo é uma via teórica privilegiada para a compreensão da experiência erótica no texto freudiano que visamos no presente artigo. Em 1905, nos "Três ensaios sobre a teoria da sexualidade" (Freud, 1905/1974), o masoquismo aponta para a idéia de uma "co-excitação", mostrando que a excitação sexual acompanha todas as produções do psiquismo, incluída aí a manifestação da dor.

A partir de 1924, o masoquismo vai tornar evidente um problema para o princípio de prazer, problema que fora levantado em 1920, no artigo "Além do princípio do prazer" (Freud, 1920/1974), onde foi apresentado o segundo dualismo pulsional, a partir da constatação da experiência da repetição.

Com efeito, a problemática da compulsão à repetição trabalhada em 1920 a partir dos jogos infantis, dos sonhos traumáticos e da repetição que ocorre na transferência analítica iniciou a discussão sobre a força da presença do pulsional no funcionamento do sujeito, radicalizando a ênfase do registro econômico para a metapsicologia. Essa discussão ganha relevo ainda maior em 1924, quando o masoquismo é explicado por meio da noção de mescla pulsional, do encontro irredutível entre Eros e pulsão de morte.

Assim, se é possível haver prazer na dor, vemos uma reviravolta na questão econômica do prazer: o princípio de prazer, que até agora regulava a nossa vida psíquica, passa a ser colocado em xeque (Freud, 1924/1974). Por isso mesmo, no título do artigo sobre o masoquismo, escrito em 1924, Freud afirma que o masoquismo é um problema para a metapsicologia quando analisado desde o ponto de vista econômico.

Portanto, podemos relacionar o registro econômico com a via do erotismo, compreendendo-se este último não estritamente como sexualidade, mas como a abordagem de um psiquismo que se constitui como um aparelho de "prazer, desprazer e angústia” (David-Ménard, 2000: 9). 
No artigo "O problema econômico do masoquismo", Freud (1924/1974) descreve três experiências subjetivas distintas: o masoquismo erógeno primordial, o masoquismo feminino e o masoquismo moral: "O masoquismo apresenta-se à nossa observação sob três formas: como condição imposta à excitação sexual, como expressão da natureza feminina e como norma de comportamento - é o masoquismo erógeno, o feminino e o moral" (Freud, [1924] 1974: 201).

Seguindo a citação acima, a experiência masoquista é apresentada em planos teóricos estruturais diferentes, que levarão a destinos pulsionais bastante diversos, como buscaremos demonstrar adiante. No momento, gostaríamos de pontuar o fato de que, em 1924, Freud apresenta a idéia de um masoquismo originário, contrapondo-se à noção que vigorava até então de que o sadismo seria primário e o masoquismo adviria como decorrência. A existência de um masoquismo originário é tributária da segunda teoria pulsional, do movimento de fusão e de desfusão pulsional entre Eros e pulsão de morte. Como Freud esclarece na frase com que abre o artigo de 1924 - "A existência de uma tendência masoquista na vida pulsional dos seres humanos pode corretamente ser descrita como misteriosa desde o ponto de vista econômico" (Freud, 1924/1974: 199) -, dizer que o masoquismo é originário tem implicaçôes no que diz respeito ao registro econômico. Portanto, o que está em questão com essa anterioridade do masoquismo em relação ao sadismo é que o ponto de vista econômico, como dissemos, vai ocupando cada vez mais uma posição de destaque na metapsicologia.

Por que não é fácil compreender uma "tendência masoquista"? Justamente porque até então os processos psíquicos eram compreendidos como sendo governados pelo princípio de prazer. O masoquismo abala a hegemonia do princípio de prazer, pois propõe que pode existir prazer em conjunto com a dor, um prazer que se dá concomitantemente ao aumento da tensão de estímulos. Diferente, portanto, do prazer de princípio, que tem como condição o rebaixamento da excitação despertada pelos estímulos.

Quando o desprazer e a dor deixam de ser somente um sinal para se transformarem eles mesmos no alvo da pulsão, isso significa que o princípio de prazer, que Freud sempre considerou o guardião da vida psíquica, fica paralisado: "é como se o vigia de nossa vida psíquica fosse colocado fora de ação por uma droga" (Freud, 1924/1974: 199). Este é o problema econômico do masoquismo: se todo o movimento da pulsão tem como finalidade a descarga, se o prazer sempre se associou a esse movimento por um princípio que visa a eliminação da excitação, então a proposta desse texto de um represamento da energia simultâneo à sensação de prazer exige uma reformulação teórica dos pressupostos que vigoravam até então. Trata-se de uma possibilidade de que o psiquismo seja capaz de manter a 
energia em um nível tal que permita advirem a dor e o desprazer, mas extraindo desse represamento uma satisfação (Schneider, 1980). Evidencia-se aqui uma figura teórica de excesso - e não de esvaziamento dos estímulos - na obra freudiana. Esse excesso tem como condição de possibilidade a circunscrição da segunda teoria pulsional, a idéia da mescla pulsional, da fusão e da desfusão entre Eros e pulsão de morte.

A libido tem a tarefa de neutralizar os poderes destrutivos da pulsão de morte e realiza isso desviando essa pulsão, em grande parte, para o exterior. Uma parte dessa pulsão, entretanto, não se associa a esse movimento de transposição para fora, ficando no organismo, sendo neste momento de encontro entre a libido e a pulsão de morte que Freud reconhece o masoquismo erógeno originário:

A libido tem a missão de tornar inócuo o instinto destruidor e a realiza desviando esse instinto, em grande parte, para fora - e em breve com o auxílio de um sistema orgânico especial, o aparelho muscular - no sentido de objetos do mundo externo. [...] Outra porção não compartilha dessa transposição para fora; permanece dentro do organismo e, com o auxílio da excitação sexual acompanhante acima descrita, lá fica libidinalmente presa. É nessa porção que temos que identificar o masoquismo original, erógeno (Freud, 1924/1974: 204).

Assim, o masoquismo originário é também erógeno, pois se constitui a partir da liga entre Eros e pulsão de morte, sendo um remanescente do momento do encontro originário entre as duas pulsões, constituindo-se a partir da porção que não é deslocada para fora do organismo.

Sobre essa descrição, é importante ressaltar aqui um movimento que é libidinal, mas que não é de descarga, pois a tensão "permanece dentro do organismo", e faz isso porque pode contar com "o auxílio da excitação sexual". Trata-se, portanto, de uma experiência de dor que é também erótica, de um modo de masoquismo que é também erotização sexual. Não por acaso, um dos qualificativos que Freud oferece para este masoquismo é o adjetivo "erógeno".

Podemos então inserir o masoquismo originário erógeno no campo do erotismo, enquanto o masoquismo feminino e o masoquismo moral são figuras da submissão e da culpabilidade. Como dissemos anteriormente, o masoquismo erógeno encontra-se em um plano estrutural teórico que difere daquele dos outros dois.

O masoquismo moral centra-se na submissão ao outro da moral - uma espécie de obediência irrestrita às injunçôes do outro social, o que levou Theodor Reik (1941) a denominá-lo de "masoquismo social". Constitui-se como um efeito do sentimento de culpa, sendo que o sofrimento aqui aparece como um destino (o que Freud denominou de "neurose de destino") que seria alheio ao sujeito, como 
obra do acaso. Enquanto o masoquismo moral é a relação do sujeito com o social, o masoquismo feminino se materializa no relacionamento com o outro, ao qual o sujeito se oferece como objeto para ser aviltado e humilhado. No masoquismo feminino, o que está em questão é a posição de humilhação frente ao objeto amoroso, pois aqui se faz necessária a encenação masoquista com o outro, diferentemente do masoquismo moral, no qual a figura do outro aparece sob a forma das injunçôes da cultura.

O masoquismo erógeno está na base dos outros dois, é sua condição de possibilidade, mas curiosamente Freud não o inscreve no campo da submissão ao outro - descreve-o a partir da mescla das pulsões, estando ao mesmo tempo em Eros e na pulsão de morte. Neste sentido, o masoquismo erógeno não se encontra nos eixos da culpabilidade e da submissão, mas se insere no campo pulsional.

Por ser explicado muito mais pela sua articulação ao campo pulsional do que por uma associação direta com o campo das representações, podemos dizer que se trata de uma figura da intensidade na obra freudiana, fora da regulação do princípio de prazer, uma vez que pode se conjugar com a culpabilidade e a submissão, mas não está restrito a estes conteúdos, apresentando-se muito mais no campo do excesso pulsional do que preso à representação e ao objeto.

É neste sentido da via pulsional que o masoquismo pode ser aproximado do erotismo. Mas é preciso, para que esta aproximação possa ser feita, diferenciar erotismo de hedonismo, já que a experiência erótica não significa a busca desenfreada do prazer. A via erótica, a nosso ver, é bem distante do masoquismo perverso, pois este último tem como finalidade o uso do outro como instrumento. $\mathrm{Na}$ experiência masoquista perversa, o gozo é calculado, e as posições dos sujeitos são dadas previamente, com a finalidade de que fiquem fixas e congeladas. Aqui, não há qualquer espaço para a experimentação. $\mathrm{O}$ masoquista realiza com o outro um pacto que procura garantir a fixidez e a imobilidade da relação. A mobilidade pulsional e a indeterminação não fazem parte do enredo masoquista, que busca prender e fixar o outro para que este possa ser explorado como instrumento de gozo do sujeito.

De maneira bem diferente, a via erótica não se dá por meio de uma fixação e congelamento do outro. Só há erotismo quando há mobilidade pulsional, e por isso o masoquismo perverso se distancia de uma via erótica. É neste sentido que propomos associar a noção de masoquismo erógeno com a experiência erótica, uma vez que esta noção está ligada, na obra freudiana, ao dualismo e à mobilidade pulsional. Por outro lado, ao ser um modo de erotismo que atua em conjunto com a dor, o masoquismo erógeno se encontra em uma região que está fora do princípio de prazer. 
É interessante, aqui, analisar esta questão do princípio de prazer na obra freudiana. Schneider (1980) faz uma leitura crítica bastante interessante dessa questão. Ela mostra como podemos entrever na teoria freudiana duas formas distintas de prazer, uma das quais estaria atrelada à regulação do princípio de prazer, e haveria outra possibilidade de prazer que não se regularia por este princípio.

O chamado princípio do prazer/desprazer reza que o aparelho psíquico possui uma tendência a abaixar o nível de excitação/estimulação que o afeta. O prazer do princípio é uma regulação automática de prazer e de desprazer, visando reduzir a tensão ao nível mais baixo possível. A função desse mecanismo é tanto evitar que irrompa no psiquismo uma quantidade excessiva de excitação, quanto salvaguardar uma reserva de energia para que o organismo possa realizar as ações específicas que garantam a sua sobrevivência. Neste sentido, o princípio de prazer se associa ao princípio de constância, que visa manter uma energia constante, que não suba a um nível muito alto que passe a acusar desprazer, mas que ao mesmo tempo não diminua a ponto de colocar em risco o psiquismo. A busca de uma constância surge como uma concessão necessária frente à urgência da vida.

O princípio de prazer freudiano é uma tendência à constância e, nesse sentido, tributário da lei da constância de Fechner e Weber, que propõe uma estabilidade entre os sistemas. Por isso mesmo, Schneider (1980) aponta que, por se constituir em uma tendência à estabilidade, o princípio de prazer é uma tentativa de eliminar a intensidade da excitação. Existe uma certa contradição em enquadrar o prazer no formato de um princípio regulador, retirando daquele tudo que poderia trazer de explosivo, de eruptivo. A autora mostra como o prazer, aqui, é um prazer da evitação, que quer neutralizar a excitação, afastar-se da intensidade, um prazer de amortecimento e neutralização: "O que esperar, portanto, de uma reflexão teórica sobre a sedução e sobre o prazer, se a operação especulativa se apresenta ela mesma como o equivalente de um cenário que visa neutralizar o prazer?” (Schneider, 1980: 87). Este prazer, segundo a autora, se esquiva da idéia de um prazer como "fruição", um prazer que possa ser experimentado positivamente e que não se defina pela negação da excitação sexual.

Mas há uma outra experiência possível do prazer na teoria freudiana. Se o princípio de prazer ocupa um lugar importante na teoria, há espaço nesta última também para um modo de prazer que não é regulado por um princípio. Trata-se de um prazer que se apresenta como potência eruptiva, que se aproxima da intensidade - o prazer como fruição - e que pode ser experimentado como uma abertura à excitação e não como um estado de evitação da excitação. Não mais o prazer do alívio e do adormecimento, mas uma experiência de despertar que faz um "consentimento à dor", isto é, um prazer que permite a presença simultânea da 
dor: "O efeito de tal prazer seria assim de despertar mais do que de adormecer, o que contrasta com a definição da satisfação como simples experiência de 'supressão’ de uma necessidade" (Schneider, 1978: 106). Pode-se entrever, então, na teoria freudiana, uma dupla relação com o prazer: "prazer que conduz ao sono, ao adormecimento, à extinção, ou prazer solidário de uma experiência de despertar e de 'renovação"' (Schneider, 1978: 127).

Esse prazer que é experimentado como intensidade tem como condição necessária o "consentimento à dor". Por isso mesmo podemos destacar a noção de masoquismo como um lugar teórico que não visa ao adormecimento da excitação. Mais do que uma relação com a dor propriamente dita, o masoquismo é uma posição de vulnerabilidade, de abertura, de acolhimento à excitação. Ao permitir a presença simultânea do prazer e da dor, o movimento do masoquismo consiste não em opor resistência à dor, mas, ao contrário disso, em "consentir à dor", abrindo a possibilidade de uma relação ao prazer que se inscreve como uma brecha na hegemonia do princípio de prazer, dessa regulação que funciona de forma unicamente defensiva frente a qualquer perturbação:

o prazer sexual pressentido na ocasião do masoquismo seria o oposto desta operação de "domínio das excitaçōes" que define o princípio do prazer: não se trata mais de "dominar" ou de "adestrar" a excitação, mas de se deixar dominar por ela. [...] É um movimento que consiste em "consentir", em não opor qualquer resistência (Schneider, 1977: 114).

Consentir à dor, portanto, significa uma atitude de entrega ao mesmo tempo ao prazer e à dor, o que dá uma abertura para o que podemos chamar de uma experiência de intensidade, que só pode ser encontrada em uma região fora do circuito de evitação da dor.

Outros exemplos que a autora destaca na teoria freudiana para a possibilidade da presença simultânea do prazer e da dor são a noção de zonas erógenas, desenvolvida em "Três ensaios para uma teoria da sexualidade" (Freud, 1905/ 1974), e a relação com a obra de arte, apresentada no texto "O Moisés de Michelangelo" (Freud, 1914/1974).

Em 1905, Freud apresenta a idéia de sexualidade perversa polimorfa a fim de demonstrar que a sexualidade humana não se restringe à finalidade genital. A libido pode se concentrar em diferentes partes do corpo, permitindo que se extraia prazer de diversas maneiras. Pela primeira vez, neste texto, aparece o conceito de pulsão, que terá como característica principal a variabilidade do seu objeto de satisfação, apontando para o polimorfismo da sexualidade. Como assinala Neri 
(2005), neste texto Freud enuncia uma proposição fundamental: a sexualidade humana não está a serviço da natureza e sim do prazer. Desta forma, a pulsão sexual se inaugura como pulsões parciais, indo contra a suposição de uma ordenação pré-estabelecida da sexualidade: "Nada na sexualidade humana está garantido, a pulsão sexual pode investir os mais diferentes objetos que lhe causem prazer, ela é variável, múltipla, dissociada da genitalidade e da reprodução da espécie" (Neri, 2005: 174).

Neste contexto da inauguração do conceito de pulsão, a noção de sexualidade perversa polimorfa inclui, assim, a possibilidade do prazer como potência. As zonas erógenas possibilitam o acréscimo da excitação em determinadas partes do corpo, o que é ao mesmo tempo fonte de um enorme prazer para a criança:

Podemos distinguir neles [nos instintos componentes] (além de um "instinto" que não é em si mesmo sexual e que tem sua origem em impulsos motores) uma contribuição de um órgão capaz de receber estímulos (p. ex. a pele, a membrana mucosa ou um órgão sensorial). Um órgão desta espécie será descrito neste sentido como uma zona erógena - como sendo o órgão cuja excitação empresta ao instinto um caráter sexual (Freud, 1905/1974: 170n; grifos nossos).

As zonas erógenas constituem-se, portanto, em regiōes corporais "intensivas", uma vez que são capazes de "receber estímulos" e não têm como meta uma perspectiva de extinção da excitação, demarcando um campo para o prazer onde este pode ser mais da ordem de uma experiência erótica do que de um princípio regulador.

Uma terceira entrada teórica para entrever o prazer intensivo na teoria freudiana é trabalhada por Schneider $(1977,1978,1980)$ a partir do texto "O Moisés de Michelangelo", de 1914 (1974).

Neste texto, Freud dá evidências do impacto que a obra de arte lhe causou, manifestando toda a vulnerabilidade que vivenciou diante da estátua de Moisés. Segundo a autora, tal vulnerabilidade, uma atitude de se sentir desarmado, perturbado, expressa a força do efeito de fascínio que a obra de arte pode exercer, sendo ela mesma uma fonte de atração e de excitação. A palavra Reiz usada por Freud neste artigo significa, no alemão, excitação, mas pode ser também charme, encanto, atração (Schneider, 1980). O Moisés encanta Freud, deixando-o desarmado frente ao excesso de estimulação proveniente da obra de arte, obrigando-o a dar evidências de uma sensação de prazer que o deixou evidentemente atordoado:

Isto me levou a reconhecer o fato - um paradoxo evidente - de que precisamente algumas das maiores e mais poderosas criações da arte constituem enigmas 
ainda não resolvidos pela nossa compreensão. Sentimo-nos cheios de admiração reverente por elas e as admiramos, mas somos incapazes de dizer o que representam para nós. Não tenho leitura suficiente do assunto para saber se esse fato já foi constatado; possivelmente, na verdade, alguém que escreva sobre estética já descobriu ser esse estado de perplexidade intelectual condição necessária para que uma obra de arte atinja seus maiores efeitos. Tenho a maior relutância em acreditar na necessidade dessa condição (Freud, 1914/1974: 253-254).

Nesta citação aparece o intenso prazer que se apossa do sujeito confrontado à obra de arte, prazer de um sujeito que se sente dominado pela força que a obra exerce sobre ele, pelo transbordamento da excitação que é experimentada diante de uma das "maiores e mais poderosas criações da arte".

Segundo Schneider, é impossível não relacionar esta atitude evocada por Freud à posição masoquista. Não estamos nos reportando aqui ao masoquismo imobilizador e ritualístico da culpabilidade e da submissão, mas a uma atitude de receptividade e de passividade que é inerente tanto à posição masoquista quanto à contemplação da obra de arte. Se nos sentimos subjugados pela obra de arte, é porque esta se apresenta como manifestação de alteridade. Enquanto a atitude masoquista dita perversa anula a possibilidade de se entregar ao poder da alteridade, a posição masoquista que remete a uma atitude de entrega, de passividade, ao "abandono a uma força exterior apreendida como transbordante, como aquilo que escapa ao domínio" (Schneider, 1978: 114), pode ser vista como uma abertura ao encanto que o outro provoca em nós.

Neste sentido, podemos perceber que os três lugares teóricos onde podemos entrever um prazer da intensidade na obra freudiana - o masoquismo, a sexualidade perversa polimorfa e a experiência estética - acabam por se encontrar em um ponto comum: a atitude de entrega do sujeito frente a uma alteridade que o perturba por ser fonte de excitação. A receptividade da experiência estética se aproxima da posição de acolhimento à dor e ao prazer inerente ao masoquismo. Já a sexualidade perversa polimorfa tem em comum com as duas primeiras a característica de uma abertura ao objeto naquilo que ele traz de inapreensível, contingente e variável. A abertura pulsional à variabilidade do objeto só é possível quando o sujeito se deixa afetar pela excitação que aquele lhe provoca.

É neste sentido que buscamos articular o masoquismo com a experiência erótica. Neste artigo, procuramos deixar claro que, para efetivar essa articulação, é necessário diferenciar o masoquismo perverso e ritualístico, cujo alvo é o uso do outro como instrumento, da posição que se refere ao masoquismo erógeno. Tratase, assim, de uma passividade, não no sentido de um sujeito que se submete e se 
assujeita ao outro, mas no sentido de poder entregar-se ao outro, de permitir-se ser afetado pela alteridade. Esta posição é erótica, pois abre a possibilidade de se viver um prazer da intensidade e não um prazer do adormecimento, um prazer que não busca anular a dor, mas que permite coexistir com ela; um prazer do qual podemos dizer que pertence ao campo da intensidade e, somente assim, ao campo do erotismo.

\section{REFERÊNCIAS BIBLIOGRÁFICAS}

David-Ménard, M. (2000). Tout le plaisir est pour moi. Paris: Hachette Littératures.

Freud, S. (1905). Três ensaios sobre a teoria da sexualidade. Obras completas, ESB, v. VII. Rio de Janeiro: Imago, 1974.

- (1914). O Moisés de Michelangelo. Obras completas, ESB, v. XIII. Rio de Janeiro: Imago, 1974.

. (1920). Além do princípio do prazer. Obras completas, ESB, v. XVIII. Rio de Janeiro: Imago, 1974.

. (1924). O problema econômico do masoquismo. Obras completas, ESB, v. XIX.

Rio de Janeiro: Imago, 1974.

Neri, R. (2005). A psicanálise e o feminino: um horizonte da modernidade. Rio de Janeiro:

Civilização Brasileira.

Reik, T. (1941). Masochism and Modern Man. New York: Farrar \& Rinehart.

Schneider, M. (1977). Freud et le plaisir: du principe à l'expérience. Topique - Revue

Freudienne, 20, 87-114.

(1978). La séduction et l'excitation consentie. Topique - Revue freudienne, 21, 105-127.

(1980). Freud et le plaisir. Paris: Denöel.

Recebido em 29 de setembro de 2007 Aceito para publicação em 30 de novembro de 2007 